\title{
Evaluation of Rigid Bronchoscopy-Guided Percutaneous Dilational Tracheostomy. A Pilot Study
}

\section{Citation}

Majid, Adnan, George Z. Cheng, Michael S. Kent, Sidhu P. Gangadharan, Richard Whyte, and Erik Folch. 2014. "Evaluation of Rigid Bronchoscopy-Guided Percutaneous Dilational Tracheostomy. A Pilot Study." Annals of the American Thoracic Society 11 (5) (June): 789-794. doi:10.1513/ annalsats.201310-343bc.

\section{Published Version}

10.1513/annalsats.201310-343bc

\section{Permanent link}

http://nrs.harvard.edu/urn-3:HUL.InstRepos:37034616

\section{Terms of Use}

This article was downloaded from Harvard University's DASH repository, and is made available under the terms and conditions applicable to Other Posted Material, as set forth at http:// nrs.harvard.edu/urn-3:HUL.InstRepos:dash.current.terms-of-use\#LAA

\section{Share Your Story}

The Harvard community has made this article openly available.

Please share how this access benefits you. Submit a story.

Accessibility 


\title{
Evaluation of Rigid Bronchoscopy-Guided Percutaneous Dilational Tracheostomy
} A Pilot Study

\author{
Adnan Majid $^{1 \star}$, George Z. Cheng ${ }^{1,2 \star}$, Michael S. Kent ${ }^{1}$, Sidhu P. Gangadharan ${ }^{1}$, Richard Whyte ${ }^{1}$, and Erik Folch ${ }^{1}$ \\ ${ }^{1}$ Division of Thoracic Surgery and Interventional Pulmonology, Beth Israel Deaconess Medical Center, Harvard Medical School, Boston, \\ Massachusetts; and 2Division of Pulmonary and Critical Care, Massachusetts General Hospital, Harvard Medical School, Boston, \\ Massachusetts
}

\begin{abstract}
Rationale: Rigid bronchoscopy-guided (RBG) percutaneous tracheostomy has been used in patients with morbid obesity, prior neck surgery, distorted airway anatomy, and uncorrected coagulopathy where standard percutaneous dilational tracheostomy (PDT) is relatively contraindicated.
\end{abstract}

Objectives: This study aims to describe a standardized approach to incorporate RBG-PDT in clinical practice.

Methods and Measurements: Retrospective case series of patients who underwent RBG-PDT from 2008 to 2012 at Beth Israel Deaconess Medical Center. Patient medical records were reviewed for demographics, comorbid conditions, American Society of Anesthesiologists classification, indication for tracheostomy, duration of procedure, and periprocedural complications.
Main Results: A total of 35 patients underwent RBG-PDT, including 24 men, with a mean age of 66 years $( \pm 11 \mathrm{yr}$; range, $42-88 \mathrm{yr}$ ). The mean body mass index was $34 \mathrm{~kg} / \mathrm{m}^{2}$. The mean procedure time was $32( \pm 10)$ minutes, with a median of 33 minutes. The most common indication for tracheostomy was failure to wean from mechanical ventilation, followed by tracheal stenosis and tracheobronchomalacia. The most common indications for RBG-PDT were complex airway, obesity, and coagulopathy. There were no periprocedural complications of consequence, or mortality associated with the procedure.

Conclusions: RBG-PDT is safe and effective in a population of high-risk patients who are otherwise not considered good candidates for standard PDT.

Keywords: airway management; tracheostomy; respiratory insufficiency

(Received in original form October 5, 2013; accepted in final form March 15, 2014)

*These authors contributed equally to the project.

Author Contributions: A.M.—conception and design, acquisition, analysis, and interpretation of data, and authoring the article; G.Z.C.—conception and design, analysis and interpretation of data, and authoring/revising the article; M.S.K.-acquisition, analysis, and interpretation of data, and revising the article; S.P.G. - acquisition, analysis, and interpretation of data, and revising the article; R.W.- -analysis and interpretation of data, and revising the article;

E.F.-conception and design, analysis and interpretation of data, and authoring/revising the article.

Correspondence and requests for reprints should be addressed to Adnan Majid, M.D., Division of Thoracic Surgery and Interventional Pulmonology, Beth Israel Deaconess Medical Center, Harvard Medical School, 185 Pilgrim Road, Deaconess-201, Boston, MA 02215. E-mail: amajid@bidmc.harvard.edu

This article has an online supplement, which is accessible from this issue's table of contents at www.atsjournals.org

Ann Am Thorac Soc Vol 11, No 5, pp 789-794, Jun 2014

Copyright (C) 2014 by the American Thoracic Society

DOI: 10.1513/AnnalsATS.201310-343BC

Internet address: www.atsjournals.org

Tracheostomy is one of the most commonly performed procedures in the intensive care unit (ICU) $(1,2)$. Since the introduction of percutaneous dilational tracheostomy (PDT) technique in 1985 , substantial advances have been made, resulting in improved safety and ease of the procedure (3). Over the past decade, the application of various imaging guidance modalities (flexible bronchoscopy, rigid bronchoscopy, and ultrasound) has further enhanced PDT and extended its use in a variety of patient populations $(4,5)$.
In a recent European study, the majority of ICU physicians (73\%) prefer to use PDT as the procedure of choice for elective tracheostomy in the ICU population requiring long-term ventilation (6). A meta-analysis examining a pool of 1,000 patients noted several outcome differences 
between surgical tracheostomy and PDT (7). Notably, there were fewer stomal wound infections, smaller neck scars, shorter procedural time, and reduction in cost with PDT. There were no significant differences in mortality, false passage creation, minor or major hemorrhage, or development of late subglottic stenosis between the techniques $(3,4,7-11)$.

PDT is easily performed through the use of the flexible or the rigid bronchoscope. However, unlike the rigid bronchoscope, the flexible bronchoscope does not provide a secure airway, can be damaged, does not provide protection to the posterior tracheal membrane, has limited suction capability, and obstructs the endotracheal tube, which may interfere with adequate ventilation. The use of rigid bronchoscopy in PDT has not been adequately described. In a review of the literature, only one case series of seven patients using rigid bronchoscopy has been reported (8). Thus, a more in-depth evaluation of the use of rigid bronchoscopy-guided (RBG) PDT to assess the utility, practicality, and safety profile is needed. Here, we present our experience in the use of RBG-PDT at our institution in patients considered at high risk for percutaneous tracheostomy. Some of the results of our study have been previously reported in abstract form (12) and were presented at the May 2012 American Thoracic Society meeting in San Francisco.

\section{Methods}

\section{Study Design and Patient Selection}

We retrospectively collected all consecutive patients who underwent RGB-PDT from January 2008 to December 2012. The study protocol was approved by the institutional review board at Beth Israel Deaconess Medical Center, Boston, Massachusetts (Protocol 2011-P-000186).

The Beth Israel Deaconess Medical Center is a tertiary-care academic facility, with a medical, surgical, trauma, cardiac, cardiothoracic, and neurologic ICU, and has a large general medical and surgical service.

We included all adult patients, 18 years or older, who suffered from acute respiratory failure requiring endotracheal intubation and mechanical ventilation, and were selected for tracheostomy placement under rigid bronchoscopy guidance for prolonged respiratory failure and failure to wean from mechanical ventilation. Patient medical records were reviewed for general demographics, comorbid medical conditions, American Society of Anesthesiology classification, indication for tracheostomy (specifically for RBG-PDT), duration of procedure, and periprocedural complications. Highrisk features, such as morbid obesity, coagulopathy, complex airway and prior neck surgery, were used for patient selection.

\section{RBG-PDT}

RBG-PDT is an elective procedure in our institution for medical and surgical patients with respiratory failure requiring tracheostomy to receive prolonged mechanical ventilatory support. Interventional pulmonologists and thoracic surgeons performed all the RBG-PDT procedures. All RBG-PDTs were performed in the operating room under general anesthesia and were monitored with continuous recording for heart rate, respiratory rate, blood pressure, oxygen saturation, and cardiac rhythm. Mechanical ventilation was maintained with fraction of inspired oxygen at 1.0 and jet ventilation.

After informed consent was obtained, the patient was brought to the operating room and placed in the supine position. A towel roll was placed between the scapulae to extend the neck. A 12-mm outer diameter rigid tracheoscope (Bryan-Dumon, Bryant Corp., Woburn, MA) was introduced orally (Figure 1A) and advanced to the posterior pharynx until the vocal cords were visualized. At that point, the rigid barrel was advanced to the glottis with the bevel anteriorly. The tip of the barrel was positioned $5 \mathrm{~mm}$ distal to the true vocal cords, and care was exercised to avoid displacement of the rigid barrel while removing the endotracheal tube from the airway (Figure 1B). The rigid tracheoscope was advanced into the subglottic area and was used to provide jet ventilation, continuous suction, and visual guidance for the remainder of the procedure (Figure 1C). After completing the exchange of the endotracheal tube for the rigid bronchoscope, the thyroid and cricoid cartilages were palpated. The tracheal rings could also be palpated and a mark was made at the second intercartilaginous space. The skin was prepped in the usual sterile fashion, and $10 \mathrm{ml}$ of lidocaine (1.5\%) with epinephrine (1:200,000 dilution) was used to anesthetize the skin and subcutaneous tissue. A 1-cm horizontal or vertical incision was performed. Through the incision, the Kelly clamp was used to dissect through the subcutaneous tissue to the anterior tracheal wall. At this point, the finder needle was introduced through the trachea and into the airway, and position was confirmed under bronchoscopic guidance. The guiding angiocath was then inserted between the second and third cartilaginous rings under bronchoscopic visualization. The needle was removed and the guide wire was introduced through the angiocath, followed by withdrawal of the angiocath. A punch dilator was introduced over the guide wire followed by the Blue Rhino (Cook Critical Care, Bloomington, IN) tapered dilator, which dilated the tracheal stoma. Then, a no. 7 or no. 8 Portex tracheostomy tube (Portex Per-fit; Smiths Medical, Dublin, $\mathrm{OH}$ ) was introduced onto a dilator and advanced into the trachea. Both the dilator and wire were withdrawn, and the tracheostomy tube was secured in place with 2-0 Prolene sutures (Prolypropylene Suture, ETHICON; Johnson \& Johnson, San Lorenzo, PR) on both sides

(Figure 1D).

\section{Results}

A total of 35 patients underwent RGB percutaneous tracheostomy placement in a 5-year period. These patients consisted of 24 men with a mean age of $66( \pm 11)$ years (range, $42-88 \mathrm{yr}$ ). The mean body mass index was $34( \pm 8) \mathrm{kg} / \mathrm{m}^{2}$, whereas

16 patients had a body mass index greater than $35 \mathrm{~kg} / \mathrm{m}^{2}$. The majority of patients (27 of 35) had an American Society of Anesthesiology classification of 4 . The most common respiratory condition was failure to wean from mechanical ventilation, followed by tracheal stenosis and tracheobronchomalacia. The most commonly recorded indications for RGBPDT were complex airway (history of difficult intubation and/or central airway obstruction), obesity, and coagulopathy. The mean procedure time was $32( \pm 10)$ minutes, with a median of 33 minutes. Two patients had bleeding quantified as greater than $10 \mathrm{ml}$, but less than $50 \mathrm{ml}$. These bleeding episodes were controlled with suction and local application of epinephrine. Two patients experienced 

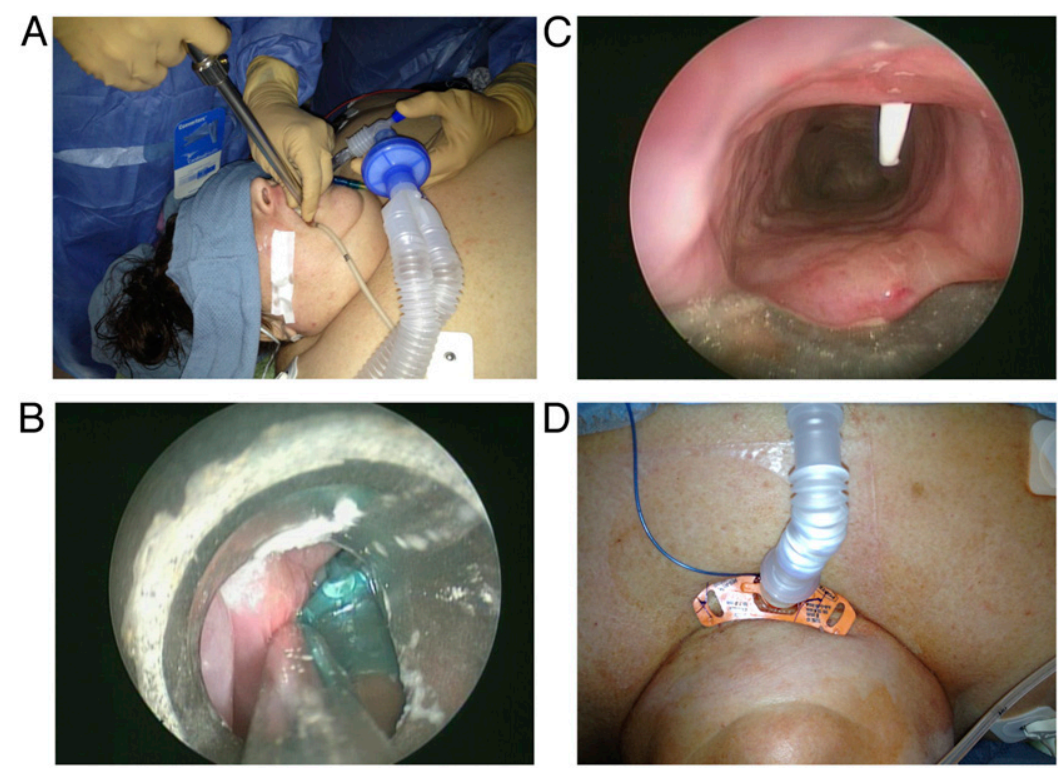

Figure 1. Rigid bronchoscopy-guided-percutaneous dilational tracheostomy in a morbidly obese patient. (A) Rigid tracheoscope was introduced orally. (B) Exchange of rigid tracheoscope with endotracheal tube. $(C)$ Jet ventilation, continuous suction and visual guidance. $(D)$ Tracheostomy tube was secured in place.

transient loss of the airway during the endotracheal tube-rigid bronchoscope exchange process; however, airway control was quickly re-established without associated hypoxemia. No major periprocedural complications or mortality was associated with the procedure. All procedures were considered successful (Table 1, Table E1).

\section{Discussion}

Percutaneous tracheostomy is a well recognized technique for establishing a long-term secure airway in the management of chronic respiratory failure that often occurs in the ICU patient population (2, 10, 13-15). Complications associated with this procedure include bleeding (external or intratracheal), false airway passage, perforation of the posterior wall, placement of high or low tracheal stomas, displacement of tracheal stents, and resultant airway obstruction. Flexible bronchoscopy guidance is commonly performed to ensure the correct placement of the tracheostomy and to identify potential immediate complications (16-19). However, flexible bronchoscopy-guided PDT has inherent limitations. These include inadequate ventilation due to occlusion of the endotracheal tube, inadvertent puncture of the cuff or the flexible bronchoscope, inability to provide adequate suction in case of massive bleed, and loss of the airway in the attempt to show the operator the adequate puncture site (20-23). In a recent report, these limitations were circumvented with suspension laryngoscopy-assisted PDT (SL-PDT) (24). There has been one report of rigid bronchoscope guidance in performing percutaneous tracheostomy (8). Our study represents the largest case series to date demonstrating the safety profile and effectiveness of RBG-PDT previously considered to have relative contraindications for PDT.

Similar to SL-PDT, we find that RBG percutaneous tracheostomy is most appropriate for patients who are morbidly obese, or have a complex airway, coagulopathy, or a history of prior surgery or radiation to the neck region. Both procedures (SL-PDT and RBG-PDT) provide improved visualization of the extratracheal operative field, control for any endotracheal bleeding, ventilation during the procedure, and exposure of the subglottic space and proximal trachea for accurate tracheostomy insertion and airway management. The major differences are in a highly selected patient population the setup of the Pilling-Weck Louie arm suspension apparatus (Pilling-Weck Surgical, Fort Washington, PA), the use of 9.0- $\mathrm{mm}$ endotracheal tube with a $5-\mathrm{mm} 30^{\circ}$ Storz rigid endoscope (Karl Stortz Endoscopy, Tuttlingen, Germany) and a Dedo laryngoscope (Pilling Surgical, Horsham, PA) for the SL-PDT (24).

Patient's body habitus can be a hindrance to tracheostomy placement (25). Rigid bronchoscopy not only offers excellent visibility during the procedure, but also displaces the trachea anteriorly to ease the access to the anterior tracheal wall and improve exposure to the puncture site. In patients with a complex airway, the rigid bronchoscope aids in maintaining a secure airway with the added ability to provide endobronchial interventions. A recent study showed that flexible PDT is safe to perform in patients with obesity. However, though statistically not significant, the patients who were morbidly obese did have double the bleeding risk when compared with the nonobese group (26). During our initial experience, two patients experienced transient loss of the airway while the endotracheal tube was being exchanged for the rigid bronchoscope. Both patients were easily intubated with the rigid bronchoscope without associated hypoxemia. To prevent this complication, we modified the technique by positioning the tip of the barrel $5 \mathrm{~mm}$ distal to the true vocal cords in the subglottic space and avoiding displacement of the rigid barrel as the endotracheal tube is removed from the airway. Since this modification, we have not experienced any additional loss of airway during the procedure.

In those patients who have uncorrectable coagulopathy, secondary to liver failure, bone marrow suppression, or clopidogrel use, the large-caliber size of the rigid bronchoscope allows for the use of interventional modalities (suction, cauterization, epinephrine injections) in case of excessive bleeding. In our cohort, two patients had bleeding that was easily controlled with suction and epinephrine.

In patients with central airway obstruction, such as in the case of tracheal or subglottic stenosis, external compression, or tracheobronchomalacia, the airways are dilated and stented open by the rigid bronchoscope. This facilitates the procedure and prevents potential catastrophic complications, such as perforation of the 
Table 1. Characteristics of patients who have undergone rigid bronchoscopy-guided percutaneous dilational tracheostomy

\begin{tabular}{|c|c|c|c|}
\hline Patient Characteristics & $\begin{array}{c}\text { Male } \\
(n=24)\end{array}$ & $\begin{array}{l}\text { Female } \\
(n=11)\end{array}$ & $\begin{array}{c}\text { Total } \\
(n=35)\end{array}$ \\
\hline $\begin{array}{l}\text { Age, } \mathrm{yr} \\
\text { BMl, } \mathrm{kg} / \mathrm{m}^{2} \\
\text { ASA score }\end{array}$ & $\begin{array}{r}66 \pm 12 \\
34.2 \pm 8.6\end{array}$ & $\begin{array}{c}67 \pm 9 \\
32.9 \pm 7.8\end{array}$ & $\begin{array}{l}66 \pm 11 \\
34 \pm 8\end{array}$ \\
\hline $\begin{array}{l}\text { ASA } 3 \\
\text { ASA } 4\end{array}$ & $\begin{array}{r}4 \\
20\end{array}$ & $\begin{array}{l}4 \\
7\end{array}$ & $\begin{array}{r}8 \\
27\end{array}$ \\
\hline $\begin{array}{l}\text { Mean procedure time, } \min \\
\text { Complications }\end{array}$ & $30 \pm 10$ & $36 \pm 8$ & $32 \pm 10$ \\
\hline $\begin{array}{l}\text { Temporary airway loss } \\
\text { Bleeding > } 10 \mathrm{cc} \\
\text { Indications for RGB-PDT }\end{array}$ & $\begin{array}{l}0 \\
2\end{array}$ & $\begin{array}{l}2 \\
0\end{array}$ & $\begin{array}{l}2 \\
2\end{array}$ \\
\hline $\begin{array}{l}\text { Complex airway } \\
\text { Coagulopathy }\end{array}$ & 7 & 7 & 14 \\
\hline $\begin{array}{l}\text { BŨN }>60, \mathrm{mg} / \mathrm{dl} \\
\text { INR }>1.5 \\
\text { PIts }<50,000 / \mu \mathrm{I} \\
\text { Clopidogrel } \\
\text { Combined }(\geqslant 2) \\
\text { Morbid obesity }\end{array}$ & $\begin{array}{r}13 \\
9 \\
3 \\
2 \\
9 \\
10\end{array}$ & $\begin{array}{l}2 \\
2 \\
2 \\
0 \\
1 \\
6\end{array}$ & $\begin{array}{r}15 \\
11 \\
5 \\
2 \\
10 \\
16\end{array}$ \\
\hline
\end{tabular}

Definition of abbreviations: ASA = American Society of Anesthesiologists score; $\mathrm{BMI}=$ body mass index; $\mathrm{BUN}=$ blood urea nitrogen; INR = international normalized ratio; Plts = platelets; RBG-PDT = rigid bronchoscopy-guided percutaneous dilational tracheostomy.

Complex airways: central airway obstruction due to strictures, tracheomalacia, or extrinsic compression. Coagulopathy: some patients had more than one risk for coagulopathy (i.e., a combination of BUN $>60 \mathrm{mg} / \mathrm{dl}$, INR $>1.5$, Plts $<50,000 / \mu \mathrm{l}$, and on Clopidogrel)

posterior membranous wall. Those patients with prior surgeries or radiation to the neck region may have altered anatomy due to scar tissue or strictures, thus requiring better exposure of the anterior tracheal wall to minimize the risk of extending the primary stenotic segment. In our series, we did not observe any increase in postoperative complications or airway compromise with concurrent RBG-PDT and treatment of tracheal obstructive lesions. In addition, by addressing central airway lesions with RBG-PDT, we are able to offer a less invasive (potentially more cost effective) approach than the surgical option involving tracheal resection, which is often avoided in patients with respiratory failure.

There are potential obstacles to widely adopting this procedure. First, this procedure requires familiarity with operating a rigid bronchoscope. Second, it requires transport of the patient from the

Table 2. Advantages and disadvantages of rigid bronchoscopy-guided percutaneous dilational tracheostomy

\section{Advantages}

1. Airway is secured.

2. Constant visualization of airway, adequate suction, and ability to provide therapeutic interventions.

3. Minimizes risk of damage to bronchoscope.

4. Protects posterior wall of the trachea; tracheal support (especially in patients with TBM).

5. Facilitates anterior displacement of the trachea, allowing easier access to the anterior tracheal wall (especially helpful in patients with morbid obesity).
ICU to the operating room. Third, if not performed by experienced operators, the airway can be lost during the exchange process. Fourth, rigid bronchoscopy may not be adaptive to a bedside procedure in many institutions (27) (Table 2).

Nevertheless, in the appropriate patient population, rigid bronchoscopy offers many advantages. First, it supports the softer structures, reducing the risk of tracheoesophageal puncture and fistula formation. Second, anterior leverage of the trachea facilitates tracheal cannulation, especially in patients who are obese. Third, in the cases of previously placed tracheal stents, the rigid bronchoscope provides a large visual field and minimizes the chance for dislodgement or compression of the stents. Furthermore, in patients with complex airways, the rigid bronchoscope provides a secure airway with excellent views without risk of cuff puncture or inadvertent dislodgement of the endotracheal tube (28). Finally, in patients with coagulopathy, the rigid bronchoscope allows easy hemostatic control. Based on these data, we propose an algorithm for selection of appropriate patients for RGB-PDT (Figure 2).

It is important to note that, out of a total 360 percutaneous tracheostomies performed in the study period, only 35 patients $(<10 \%)$ underwent RGB-PDT. We were very selective, especially with patients who were morbidly obese. Contrary to the prior reports on the significant complications of PDT in patients who were morbidly obese (29), we observed a $6.5 \%$ complication rate similar to that reported by Heyrosa and colleagues (30). The issue of poor anatomical landmarks in the patient who is morbidly obese is reduced with the use of rigid bronchoscopy.

The major limitation in our study was the lack of direct comparison between RBGPDT and that of flexible bronchoscopyguided PDT. Thus, we are unable to prove a benefit of using the rigid bronchoscope in PDT. However, we do provide the setup and feasibility for future investigations involving use of the rigid bronchoscope in a specified high-risk population. The superiority in using rigid bronchoscopic guidance can only be definitely addressed with future randomized controlled clinical trials. Another limitation in our study is the lack of cost-effectiveness analysis. However, based on previous studies comparing 


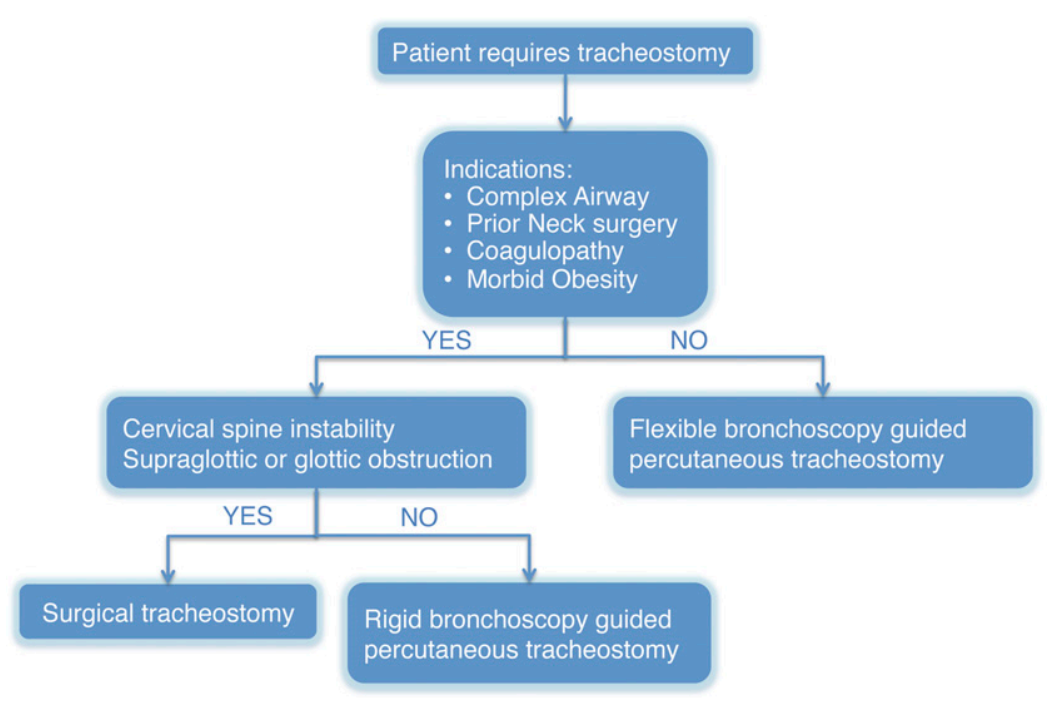

Figure 2. Proposed patient selection algorithm for rigid bronchoscopy-guided-percutaneous dilational tracheostomy.

open and percutaneous tracheostomy, it is estimated that the percutaneous tracheostomy had significantly lower wound infection, less unfavorable scarring, shorter procedural time (by $4.6 \mathrm{~min}$ ), and cost approximately $\$ 456$ USD less than the open tracheostomy $(7,31)$. The third limitation of our current setup involves transporting of patients to the operating room. Although prior studies have reported that transport of critically ill patients can carry a risk of significant adverse events ranging from 4 to $8 \%$ (32), we did not observe any complications related to transportation. Fourth, the need of a well trained bronchoscopist to use rigid bronchoscopy can limit the availability of the procedure. However, in the last decade, rigid bronchoscopy has been gaining popularity, largely due to the increasing numbers of practicing interventional pulmonologists. In the near future, the procedures involving the use of rigid bronchoscopy are projected to be more widespread. Finally, the learning period for PDT is shorter than for surgical tracheostomy (33). This may favorably impact the implementation of RBG-PDT in patients previously considered at high risk for percutaneous approach.

Our study offers a single-center experience with RBG-PDT, not as a replacement, but, rather, as an adjunct to the current spectrum of available care, which includes FBG-PDT, SL-PDT, and open tracheostomy. To truly demonstrate the value of RBG-PDT, future randomized clinical trials are needed to compare the RBG-PDT to the current standard of care in terms of safety, indications, and cost effectiveness. In the largest case series to date, we demonstrate that RBG-PDT is safe and effective when performed by experienced bronchoscopists in a population of high-risk patients who are otherwise not considered good candidates for standard PDT. As an intermediate step between percutaneous and surgical tracheostomy, we propose a strategy to incorporate rigid bronchoscope use in PDT for a selected patient population with morbid obesity, complex airways, and/or coagulopathy.

Author disclosures are available with the text of this article at www.atsjournals.org.

Acknowledgment: The authors thank Drs. Colleen Keyes, Jorge Guerrero, and Evan Baley for their help in image acquisition.

\section{References}

1 Rana S, Pendem S, Pogodzinski MS, Hubmayr RD, Gajic O. Tracheostomy in critically ill patients. Mayo Clinic Proc 2005;80: 1632-1638.

2 Phua GC, Wahidi MM. ICU procedures of the critically ill. Respirology 2009;14:1092-1097.

3 Cabrini L, Monti G, Landoni G, Biondi-Zoccai G, Boroli F, Mamo D, Plumari VP, Colombo S, Zangrillo A. Percutaneous tracheostomy, a systematic review. Acta Anaesthesiol Scand 2012;56:270-281.

4 Susarla SM, Peacock ZS, Alam HB. Percutaneous dilatational tracheostomy: review of technique and evidence for its use. J Oral Maxillofac Surg 2012;70:74-82.

5 Rajajee V, Fletcher JJ, Rochlen LR, Jacobs TL. Real-time ultrasound-guided percutaneous dilatational tracheostomy: a feasibility study. Crit Care 2011;15:R67.

6 Groves DS, Durbin CG Jr. Tracheostomy in the critically ill: indications, timing and techniques. Curr Opin Crit Care 2007;13:90-97.

7 Higgins KM, Punthakee X. Meta-analysis comparison of open versus percutaneous tracheostomy. Laryngoscope 2007;117:447-454.

8 Grigo AS, Hall ND, Crerar-Gilbert AJ, Madden BP. Rigid bronchoscopy-guided percutaneous tracheostomy. $\mathrm{Br} J$ Anaesth 2005;95:417-419.

9 Delaney A, Bagshaw SM, Nalos M. Percutaneous dilatational tracheostomy versus surgical tracheostomy in critically ill patients: a systematic review and meta-analysis. Crit Care 2006;10:R55.
10 Mallick A, Bodenham AR. Tracheostomy in critically ill patients. Eur $J$ Anaesthesiol 2010;27:676-682.

11 Pappas S, Maragoudakis P, Vlastarakos P, Assimakopoulos D, Mandrali T, Kandiloros D, Nikolopoulos TP. Surgical versus percutaneous tracheostomy: an evidence-based approach. Eur Arch Otorhinolaryngol 2011;268:323-330.

12 Cheng G, Kent M, Gangadharan S, Folch E, Majid A. Rigid bronchoscopy guided percutaneous dilational tracheostomy: a single institution experience [abstract]. D54 Topics in interventional pulmonology: American Thoracic Society; 2012. A5921.

13 Meininger D, Walcher F, Byhahn C. Tracheostomy in intensive care long-term ventilation: indications, techniques and complications [article in German]. Chirurg 2011;82:107-110, 112-115.

14 Durbin CG Jr. Tracheostomy: why, when, and how? Respir Care 2010;55:1056-1068.

15 Baumann HJ, Kemei C, Kluge S. Tracheostomy in the intensive care unit [article in German]. Pneumologie 2010;64:769-776.

16 Kost KM. Endoscopic percutaneous dilatational tracheotomy: a prospective evaluation of 500 consecutive cases. Laryngoscope 2005;115:1-30.

17 Beiderlinden M, Groeben H, Peters J. Safety of percutaneous dilational tracheostomy in patients ventilated with high positive end-expiratory pressure (PEEP). Intensive Care Med 2003;29:944-948.

18 Oberwalder M, Weis H, Nehoda H, Kafka-Ritsch R, Bonatti $H$, Prommegger R, Aigner F, Profanter C. Videobronchoscopic guidance makes percutaneous dilational tracheostomy safer. Surg Endosc 2004;18:839-842. 
19 Dongelmans DA, Tepaske R, Schultz MJ. Assessment of ventilation during the performance of elective endoscopic-guided percutaneous tracheostomy. Chest 2005;127:2290-2291, author reply 2291-2292.

20 Al-Ansari MA, Hijazi MH. Clinical review: percutaneous dilatational tracheostomy. Crit Care 2006;10:202.

21 De Leyn P, Bedert L, Delcroix M, Depuydt P, Lauwers G, Sokolov Y, Van Meerhaeghe A, Van Schil P; Belgian Association of Pneumology and Belgian Association of Cardiothoracic Surgery. Tracheotomy: clinical review and guidelines. Eur J Cardiothorac Surg 2007; 32:412-421.

22 Brander L, Takala J. Tracheal tear and tension pneumothorax complicating bronchoscopy-guided percutaneous tracheostomy. Heart Lung 2006;35:144-145.

23 Beiderlinden M, Karl Walz M, Sander A, Groeben H, Peters J. Complications of bronchoscopically guided percutaneous dilational tracheostomy: beyond the learning curve. Intensive Care Med 2002;28:59-62.

24 White HN, Sharp DB, Castellanos PF. Suspension laryngoscopyassisted percutaneous dilatational tracheostomy in high-risk patients. Laryngoscope 2010;120:2423-2429.

25 Ernst A, Critchlow J. Percutaneous tracheostomy-special considerations. Clin Chest Med 2003;24:409-412.

26 McCague A, Aljanabi H, Wong DT. Safety analysis of percutaneous dilational tracheostomies with bronchoscopy in the obese patient. Laryngoscope 2012;122:1031-1034.
27 Polderman KH, Spijkstra JJ, de Bree R, Christiaans HM, Gelissen HP, Wester JP, Girbes AR. Percutaneous dilatational tracheostomy in the ICU: optimal organization, low complication rates, and description of a new complication. Chest 2003;123:1595-1602.

28 Pratt T, Bromilow J. Laryngeal mask airway for airway control during percutaneous dilatational tracheostomy. Anaesth Intensive Care 2011;39:1009-1013.

29 Byhahn C, Lischke V, Meininger D, Halbig S, Westphal K. Peri-operative complications during percutaneous tracheostomy in obese patients. Anaesthesia 2005;60:12-15.

30 Heyrosa MG, Melniczek DM, Rovito P, Nicholas GG. Percutaneous tracheostomy: a safe procedure in the morbidly obese. J Am Coll Surg 2006;202:618-622.

31 Bacchetta MD, Girardi LN, Southard EJ, Mack CA, Ko W, Tortolani AJ, Krieger KH, Isom OW, Lee LY. Comparison of open versus bedside percutaneous dilatational tracheostomy in the cardiothoracic surgical patient: outcomes and financial analysis. Ann Thorac Surg 2005;79:1879-1885.

32 Fanara B, Manzon C, Barbot O, Desmettre T, Capellier G. Recommendations for the intra-hospital transport of critically ill patients. Crit Care 2010;14:R87.

33 Massick DD, Powell DM, Price PD, Chang SL, Squires G, Forrest LA, Young DC. Quantification of the learning curve for percutaneous dilatational tracheotomy. Laryngoscope 2000; 110:222-228. 